\title{
THE CHARACTERISTICS AND POTENTIAL SOURCE AREA ANALYSIS OF PM 2.5 CONCENTRATION FOR ZHENGZHOU DURING 2016
}

\author{
Li Dongpu , Liu Junjie , Li Sijie, Wang Chuang, Zhou Shenghui * \\ College of Environment and Planning, Henan University, Kaifeng, Henan, China - shenghui321@163com
}

KEY WORDS: $\mathrm{PM}_{2.5}$, Backward Trajectory, Cluster Analysis, Potential Source Area, Zhengzhou

\begin{abstract}
:
This study used the HYSPLIT-4 model combined with cluster analysis, potential source pollution contribution functions and other methods to analyse the ground air pollution monitoring data and meteorological data in Zhengzhou during 2016. The results showed that: 1) the level of $\mathrm{PM}_{2.5}$ reached the low value in summer. The $\mathrm{PM}_{2.5}$ concentration reached the highest level in December and reached the lowest level in August. The daily variation characteristics of $\mathrm{PM}_{2.5}$ concentration in different seasons were roughly the same, and it had an obviously "double-peak" structure. 2) The annual $\mathrm{PM}_{2.5}$ concentration was positively correlated with atmospheric pressure and relative humidity. The annual $\mathrm{PM}_{2.5}$ concentration was negatively correlated with temperature, visibility, precipitation, and wind speed. 3) In winter, the air mass trajectory that through the northern Sichuan - Gansu - Shaanxi - Hubei was polluted seriously, and the level of $\mathrm{PM}_{2.5}$ was the highest which reached to $202.13 \mu \mathrm{g} / \mathrm{m}^{3}$. In summer, the air mass trajectory that came from Hubei was the lowest level with the value is $40.17 \mu \mathrm{g} / \mathrm{m}^{3}$. 4) The potential source areas located in northwest of Zhengzhou, Gansu, Hubei and Beijing-Tianjin-Hebei region in spring. The surrounding of Zhengzhou contributed to the pollution of Zhengzhou. The potential source areas appeared in Shaanxi, Sichuan, and Qinghai, the border between Ningxia and Inner Mongolia in autumn. In winter the potential source areas located in Jiangsu, Hubei, Henan, eastern of Shanxi, southern of Shanxi, Ningxia and the area of Yellow Sea, etc.
\end{abstract}

\section{INTRODUCTION}

With the rapid development of social economy, the increasingly prominent air pollution problem has seriously damaged the existing ecosystem and human health (Ke et al., 2014; Ma et al., 2017; Zhou et al., 2017b). The study about the concentration change characteristics of $\mathrm{PM}_{2.5}$ and cross-regional transmission has also attracted widespread attention (Ge et al., 2017; Wang et al., 2016; Zhao et al., 2017). The analysis of atmospheric pollutants and the study of potential source areas are mainly concentrated in Beijing-Tianjin-Hebei(Wang et al., 2014), Yangtze River Delta(Wang et al., 2013; Xia et al., 2013; Zhu et al., 2017), and Pearl River Delta regions. In the numerical simulation of pollutant diffusion, the HYSPLIT model was developed by the National Oceanic and Atmospheric Administration's (NOAA) Air Resources Laboratory and the Australian Meteorological Administration to calculate and analyse atmospheric pollutant transport trajectories and diffusion concentrations. The professional models are widely used to describe atmospheric transport and diffusion simulations, as well as the deposition of pollutants and harmful substances(Jiang et al., 2013).

Based on the mentioned technical method, the problem of pollutant transmission in cities and regions where the air pollution is serious has been studied. Ren Chuanbin et al. used the HYSPLIT-4 backward trajectory model to find that seasonal characteristics of the $\mathrm{PM}_{2.5}$ transport route in Beijing urban area are obvious, and the contribution of different transport routes to urban $\mathrm{PM}_{2.5}$ in Beijing is significantly different(Ren et al., 2016). He Tao and others used the HYSPLIT-4 model to study the impact of different air mass sources on the concentrations of various pollutants in Changzhou and the distribution characteristics of potential pollution sources. The results showed that: there was severe $\mathrm{PM}_{2.5}$ pollution in Changzhou in winter, which may related to incomplete combustion. The analysis of the continental air flow in Southwest China has a greater impact(He et al.2017). Wang Fang et al. found that the low-level atmospheric transport of seasonal changes in the Pearl River Delta region was significant, and the serious air pollution in Guangzhou was affected by surrounding cities(Wang et al., 2009a). Zhao Zijing et al. analysed the correlation between haze and main meteorological conditions in Nanjing. The HYSPLIT4 model was used to analyse the trajectory of the air mass. And they made use of meteorological factors to analyse the process and sources of pollutant diffusion and transportation(Zhao et al., 2015b). Wang et al., confirmed that the PSCF analysis and CWT analysis can determine the potential sources of contamination and the degree of contamination well(Wang et al., $2009 \mathrm{~b}$ ). Wang et al. demonstrated that it can be better to combine trajectory clustering with potential source area analysis to understand the impact of different areas on pollutant transportation(Wang et al., 2015).

By using the ground air pollution monitoring data and the NCEP reanalysis data of 2016, the HYSPLIT-4 model, clustering analysis and the Potential Source Contribution Function methods were adopted to simulate the variance of $\mathrm{PM}_{2.5}$ in different time scales and seasons. And we used the meteorological factors (temperature, pressure, relative humidity, visibility and wind speed) to study the impacts on $\mathbf{P M}_{2.5}$ concentrations. By using statistical methods such as cluster analysis and potential source contribution function (PSCF), the potential source areas that have made contribution to pollute Zhengzhou were searched. Therefore, we can provide suggestions for air pollution warning in Zhengzhou.

\footnotetext{
*Corresponding author
} 


\section{DATA SOURCES AND RESEARCH METHODS}

\subsection{Data Sources}

The air pollution monitoring data and meteorological data were obtained from the Yellow River Downstream Scientific Data Centre (http://henu.geodata.cn). The data includes in $\mathrm{PM}_{2.5}$, $\mathrm{PM}_{10}, \mathrm{SO}_{2}, \mathrm{CO}, \mathrm{NO}_{2}, \mathrm{O}_{3}$ and etc. The air quality data of Zhengzhou was selected for analysis during 2016. The data of the backward trajectory model is the FNL global analysis data that is provided by the Global Data Assimilation System (GDAS) of the National Centres for Environmental Prediction (NCEP). The gas field resolution is $191 \mathrm{~km} \times 191 \mathrm{~km}$. The data was converted into the required format by ARL (NOAA Air Resources Laboratory)'s pre-processing module. In this study, weather data is updated four times per day, and the horizontal resolution is $1^{\circ} \times 1^{\circ}$.

\subsection{Research Methods}

2.2.1 HYSPLIT Track Mode. The HYSPLIT-4 model is based on the Eulerian-Largangian hybrid diffusion model, which is developed by the National Oceanic and Atmospheric Research Centre (NOAA) of the United States. The diffusion calculation uses the Largangian method. The variable grid can define the pollution source. The model uses the Eulerian method to calculate the concentration of pollutants on a fixed grid(Budge, 2004). Because the model has the ability to calculate forwards and backwards, it can simulate and predict pollutants' trajectories, diffusion, wet and dry settlements. It can be used not only evaluate the source of pollutants, but also can simulate and predict pollutant emissions. The vector velocity of mass point is derived from the linear interpolation in both time and space(Cape et al., 2000). The trajectory of the air mass's position can be described as:

$$
\begin{gathered}
\mathrm{P}^{\prime}(\mathrm{t}+\Delta \mathrm{t})=\mathrm{P}(\mathrm{t})+\mathrm{V}(\mathrm{P}, \mathrm{t}) \Delta \mathrm{t} \\
\mathrm{P}(\mathrm{t}+\Delta \mathrm{t})=\mathrm{P}(\mathrm{t})+0.5\left[\mathrm{~V}(\mathrm{P}, \mathrm{t})+\mathrm{V}\left(\mathrm{P}^{\prime}, \mathrm{t}+\Delta \mathrm{t}\right)\right]
\end{gathered}
$$

$\mathrm{P}$ refers to the location of the particle; $\mathrm{V}$ refers to the vector velocity at the location of the particle; $t$ refers to the time of the particle's movement. The position of the next point is determined by the average speed at the previous moment and the first guessed value's speed, and they are averaged. Finally the result should multiply the time step together.

In this study, we used the HYSPLIT- 4 model and TrajStat. The starting point of the trajectory is $113.65^{\circ} \mathrm{E}, 34.76^{\circ} \mathrm{N}$. The altitude is $500 \mathrm{~m}$ from the ground(Yan et al.; Zhao et al., 2009), and we calculate 72 hours backwards to simulate $\mathrm{PM}_{2.5}$ in Zhengzhou. The aim is to stimulate cross-regional transportation routes and potential source area.
2.2.2 Cluster Analysis. Cluster analysis is a quantitative method of the sample's own attributes. According to the similarity or differences, cluster analysis determines the intimacy between the samples, and in accordance with the relationship between the samples to cluster. In this study, we used the Euclidean distance in TrajStat to cluster the airflow trajectory, and the system clustering used Word's minimum variance method. Therefore we can attain different types of air flow in Zhengzhou in four seasons.

2.2.3 Potential Source Contribution Analysis. PSCF analysis method (potential source contribution analysis) mainly uses the backward trajectory to calculate and describe the location of potential source regions. And PSCF reflects the delay time of air masses in certain spatial coverage before air masses reach the study area. The PSCF value is the ratio of the number of contaminated tracks $\left(m_{i j}\right)$ passing through the mesh and the number of all tracks traversed on the mesh $\left(n_{i j}\right)$ (Zhao et al., 2015a):

$$
P S C F_{i j}=m_{i j} / n_{i j}
$$

The study area $\left(26^{\circ} \mathrm{N} \sim 45^{\circ} \mathrm{N}, 102^{\circ} \mathrm{E} \sim 125^{\circ} \mathrm{E}\right)$ was divided into the grids of $0.1^{\circ} \times 0.1^{\circ}$, and the probability of mass trajectories within each grid was calculated. The threshold is $75 \mu \mathrm{g} / \mathrm{m}^{3}$

( 《Ambient Air Quality Standard》 (GB 3095-2012) requires that the daily average level of $\mathrm{PM}_{2.5}$ is $75 \mu \mathrm{g} / \mathrm{m}^{3}$ ). When the value of trajectory is higher than the threshold, it is considered as pollution trajectory; otherwise it is a clean trajectory. Since PSCF is a conditional probability, the value of PSCF is uncertain when delay time of air masses in each grid is short ( $n_{i j}$ is small). Therefore some scholars have introduced the empirical weight function (W $\left(n_{i j}\right)$ ) to perform interval weighting and reduce errors(He et al.; Wang, 2014; Zhou et al., 2017a). When the number of trajectories in the grid less three times than the average of the trajectories of the points. We used (W $\left(n_{i j}\right)$ ) to reduce the uncertainty of the PSCF. This article refers the specific weighting function (He et al.; Polissar et al., 2001; Zhao et al., 2015a):

$$
\begin{gathered}
W_{\left(n_{i j}\right)}=\left\{\begin{array}{lr}
1.0 & 80<n_{i j} \\
0.7 & 20<n_{i j} \leq 80 \\
0.42 & 10<n_{i j} \leq 20 \\
0.05 & n_{i j} \leq 10
\end{array}\right. \\
W P S C F_{i j}=P S C F_{i j} \times W_{\left(n_{i j}\right)}
\end{gathered}
$$

The number of pollution trajectories is more, and the value of WPSCF$_{\mathrm{ij}}$ will become higher. The potential source area of $\mathrm{PM}_{2.5}$ pollution in Zhengzhou corresponds to the high WPSCF $_{\mathrm{ij}}$.

3.THE ATMOSPHERE POLLUTION PROCESS

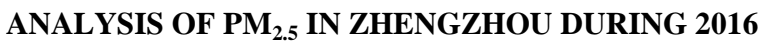




\subsection{Analysis on the Change Characteristics of $\mathbf{P M}_{2.5}$ Concentration in Zhengzhou during 2016}

3.1.1 Analysis on Diurnal Variation of $\mathbf{P M}_{2.5}$ Concentration in Zhengzhou during 2016. In addition to the diurnal variation in different seasons of Zhengzhou during 2016 (Figure 1), the average value of $\mathrm{PM}_{2.5}$ is less than $100 \mu \mathrm{g} / \mathrm{m}^{3}$. The average value of $\mathrm{PM}_{2.5}$ in the winter was the highest and the most level $\mathrm{PM}_{2.5}$ concentration in the summer was the lowest comparing with other periods. The hourly average value of $\mathrm{PM}_{2.5}$ concentration in the winter was higher than $120 \mu \mathrm{g} / \mathrm{m}^{3}$, and the hourly average value of $\mathrm{PM}_{2.5}$ concentration in the spring, summer and autumn were lower than the hourly average value of $\mathrm{PM}_{2.5}$ concentration in all period which was lower than $100 \mu \mathrm{g} / \mathrm{m}^{3}$. The average $\mathrm{PM}_{2.5}$ concentrations in the spring and autumn were not significantly different, apart from after 10 a.m. when the $\mathrm{PM}_{2.5}$ concentration in the autumn was higher than the hourly average of $\mathrm{PM}_{2.5}$ concentration in the spring. The daily variations of $\mathrm{PM}_{2.5}$ concentrations in different seasons were roughly the same, with an obvious "double peak" structure that The $\mathrm{PM}_{2.5}$ concentration increased from 0 to 8 a.m. and reached its first peak at 8 o'clock in the morning. Afterwards, the concentration of $\mathrm{PM}_{2.5}$ decreased from 8 a.m. to 17 p.m. and it reached the lowest value of the day at 17 p.m. Finally, The $\mathrm{PM}_{2.5}$ concentration increased from 17 p.m. to 23 p.m. and reached its second peak at 23 p.m.

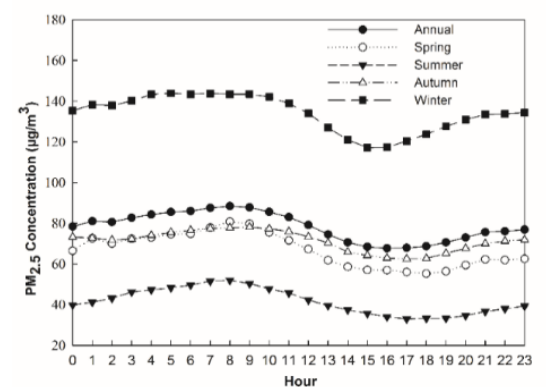

Figure1 Diurnal Variation of $\mathrm{PM}_{2.5}$ Concentration in Different Seasons in Zhengzhou during 2016

3.1.2 Analysis of the Monthly and Seasonal Changes of $\mathbf{P M}_{2.5}$ Concentration in Zhengzhou City in 2016. By the statistic on the characteristics of $\mathrm{PM}_{2.5}$ monthly changes in Zhengzhou in 2016 (Figure 2), we find that the characteristics of $\mathrm{PM}_{2.5}$ showed a "U" distribution. The $\mathrm{PM}_{2.5}$ concentration reached the highest in Zhengzhou in December 2016 that the average concentration reached $161 \mu \mathrm{g} / \mathrm{m}^{3}$. And the frequency of heavy polluted days was also higher in January that the average $\mathrm{PM}_{2.5}$ concentration reached $156 \mu \mathrm{g} / \mathrm{m}^{3}$. From January to July, the concentration of $\mathrm{PM}_{2.5}$ showed a downward trend and $\mathrm{PM}_{2.5}$ concentration in July was the lowest month of the year. Then, $\mathrm{PM}_{2.5}$ concentration increased from July to December. From the Seasonal variation characteristics of $\mathrm{PM}_{2.5}$ in Zhengzhou in 2016 (Figure 3), we find that seasonal variation characteristics of $\mathrm{PM}_{2.5}$ also had an obvious seasonal differences: the concentration of $\mathrm{PM}_{25}$ was the highest in the winter, followed by the spring and autumn. In the summer, the concentration of $\mathrm{PM}_{2.5}$ was the lowest and the average concentration was lower than $50 \mu \mathrm{g} / \mathrm{m}^{3}$.

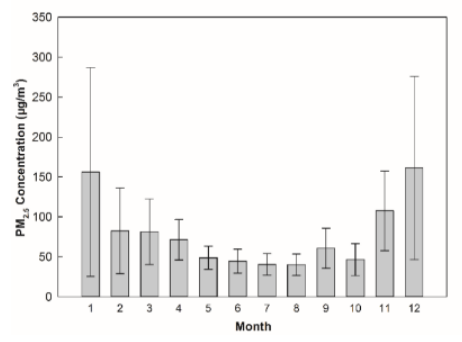

Figure2 The $\mathrm{PM}_{2.5}$ Monthly Changes in Zhengzhou during 2016

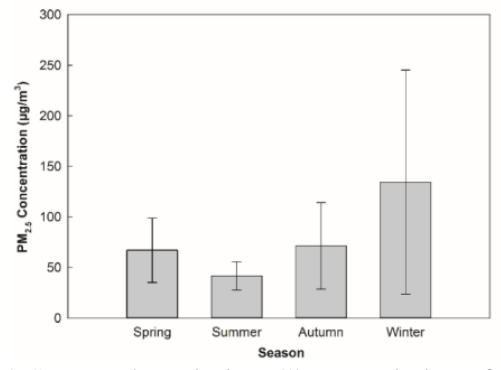

Figure3 Seasonal Variation Characteristics of $\mathrm{PM}_{2.5}$ in Zhengzhou during 2016

\subsection{Relationship between $\mathbf{P M}_{2.5}$ Concentration and Meteorological Factors}

Meteorological elements are important factors that affect the concentration of $\mathrm{PM}_{2.5}$. Temperature, wind speed, atmospheric pressure, relative humidity, and precipitation affect the dilution, diffusion, and transfer of pollutants in the urban atmosphere. Therefore, understanding the mechanism of meteorological conditions affecting the concentration of $\mathrm{PM}_{2.5}$ facilitates related prevention and control work. The Pearson correlation analysis (Table 1) and the change over time of the $\mathrm{PM}_{2.5}$ and meteorological factors in Zhengzhou during 2016 have been done (Figure 4).

\subsubsection{Effect of Temperature on $\mathbf{P M}_{2.5}$ Concentration.}

From the whole year, the temperature has a significantly negative correlation with the level of $\mathrm{PM}_{2.5}$. The increase in temperature is conducive to the enhancement of atmospheric thermal conditions, which intensifies the convective movement in the atmospheric troposphere, and enhances the transport and diffusion capacity of the atmosphere(Yang et al., 2017). And it is beneficial to particle transfer. However, there is a weak correlation between temperature and $\mathrm{PM}_{2.5}$ concentration in autumn. Correlation analysis between summer and winter shows that temperature is not related to $\mathrm{PM}_{2.5}$ concentration, the result of which may be that the summer temperature is higher than others and the particle concentration is generally lower and winter temperature is lower and particulate concentration is generally high (Figure 4). 
3.2.2 Effect of Wind Speed on $\mathbf{P M}_{2.5}$ Concentration. Wind is an important factor affecting the spread of $\mathrm{PM}_{2.5}$, and wind speed affects the speed of $\mathrm{PM}_{2.5}$ transport. To a certain extent, the higher the wind speed, the more conducive to the diffusion of $\mathrm{PM}_{2.5}$, the farther the pollutants are transported in a unit of time, the more uniformly they mix with the air, thus reducing the $\mathrm{PM}_{2.5}$ concentration in the ambient air. From Table 1, we can see that there is a strong negative correlation between wind speed and $\mathrm{PM}_{2.5}$ concentration, regardless of the year or season, which is consistent with the results shown in Fig. 4 that basically reflect the opposite trend of annual wind speed and $\mathrm{PM}_{2.5}$ concentration.

3.2.3 Effect of Air Pressure on $\mathbf{P M}_{2.5}$ Concentration. For the whole year, there was a significant positive correlation between barometric pressure and $\mathrm{PM}_{2.5}$ concentration; there was no significant correlation between $\mathrm{PM}_{2.5}$ concentration and barometric pressure in spring, summer and autumn, but a significant negative correlation in winter. When the ground is under the control of low pressure, high-pressure air around the center flows to the center, so that the center forms an updraft, forming a strong wind, conducive to upward diffusion of pollutants, $\mathrm{PM}_{2.5}$ concentration is low. On the contrary, if the ground is subjected to high pressure control, subsidence flow occurs at the center and the upward diffusion of pollutants is inhibited. Under the control of stable high pressure, pollutants are easily accumulated and the concentration of $\mathrm{PM}_{2.5}$ is increased(Mu et al., 2011), so the concentration of $\mathrm{PM}_{2.5}$ is higher in winter.
3.2.4 Effect of Relative Humidity on $\mathbf{P M}_{2.5}$ Concentration. From the whole year, the $\mathrm{PM}_{2.5}$ concentration was positively correlated with relative humidity, and the correlation between $\mathrm{PM}_{2.5}$ mass concentration and relative humidity was highest in the winter ( $\mathrm{r}=0.361$ ). In a certain range of humidity (without the occurrence of gravity settlement), relative humidity is likely to cause particulate matter to accumulate(Liu et al., 2016). Since Zhengzhou is in a relatively dry north, the humidity in the atmosphere will not be too large, so the $\mathrm{PM}_{2.5}$ concentration and relative humidity are positively correlated at any time scale.

3.2.5 Relationship between Visibility and $\mathbf{P M}_{2.5}$ Concentration. Research results show that particulate matter in the atmosphere is an important reason for reducing visibility(Song et al., 2003). It can be clearly seen from Table 1 and the figure 6 that there is a significant strong negative correlation between visibility and concentration of $\mathrm{PM}_{2.5}$, with the strongest correlation in spring $(r=-0.760)$ and similar levels in other seasons. In the summer, the concentration of $\mathrm{PM}_{2.5}$ is low, and the visibility is the highest; in the winter, the concentration of $\mathrm{PM}_{2.5}$ is high, and the visibility is the lowest. Visibility is affected by the concentration of fine particles is very obvious.

3.2.6 Effect of Precipitation on $\mathbf{P M}_{2.5}$ Concentration. Seasonal precipitation was negatively correlated with $\mathrm{PM}_{2.5}$ concentration, but there was no significant correlation between spring, summer and winter. Precipitation has the effect of removing pollutants, and particulate matter can be washed by precipitation to the ground(Luo et al., 2017), thus reducing the concentration of $\mathrm{PM}_{2.5}$ in the ambient air. Zhengzhou has a temperate monsoon climate, with high temperatures and rain in summer and cold, dry winters. Precipitation contributes to the reduction of $\mathrm{PM}_{2.5}$ concentrations in summer.

\begin{tabular}{cccccc}
\hline meteorological factors & Spring & Summer & Autumn & Winter & Year \\
\hline Temperature & $-0.236^{*}$ & -0.091 & $-0.248^{*}$ & -0.054 & $-0.458^{* *}$ \\
wind speed & $-0.453^{* *}$ & $-0.376^{* *}$ & $-0.412^{* *}$ & $-0.432^{* *}$ & $-0.388^{* *}$ \\
atmospheric pressure & -0.039 & 0.008 & 0.049 & $-0.210^{*}$ & $0.302^{* *}$ \\
relative humidity & 0.183 & 0.036 & $0.263^{*}$ & $0.361^{* *}$ & $0.164^{* *}$ \\
visibility & $-0.760^{* *}$ & $-0.590^{* *}$ & $-0.547^{* *}$ & $-0.579^{* *}$ & $-0.565^{* *}$ \\
precipitation & -0.177 & -0.097 & $-0.224^{*}$ & -0.114 & $-0.110^{*}$ \\
\hline
\end{tabular}

“*”and“***"means passing the confidence testing at $\alpha=0.05$ and $\alpha=0.01$, respectively. $n=4732$

Table 1 Correlation between $\mathrm{PM}_{2.5}$ and meteorological factors

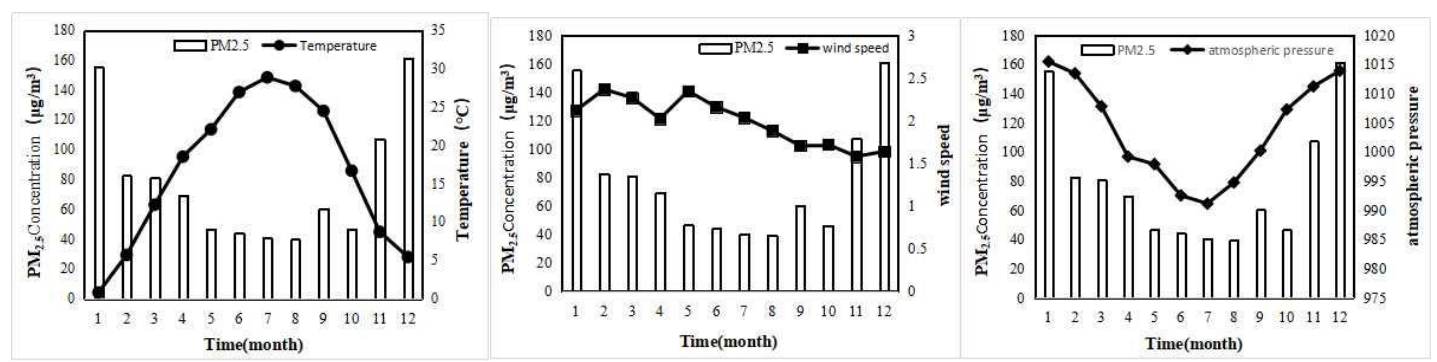



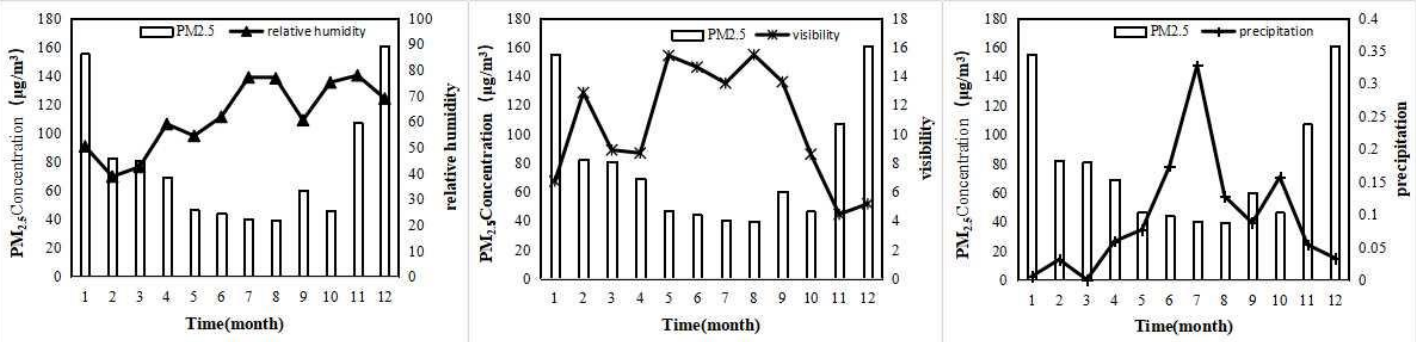

Figure 4 The relationship between $\mathrm{PM}_{2.5}$ Concentration and Meteorological Elements

\subsection{Backward Clustering Analysis}

In order to reveal the differences of the air mass in Zhengzhou in different seasons, cluster analysis was performed for each season. Combined with air pollution monitoring data, the air mass of each season was divided into 6 categories, and we calculated the average value and the weight of the level of $\mathrm{PM}_{2.5}$ The regional characteristics of various types of $\mathrm{PM}_{2.5}$ are shown in Figure 5 is trajectory classification. From the clustering results, it can be found that the seasonal variation of air mass trajectory is obvious and the average value of $\mathrm{PM}_{2.5}$ in winter is the highest, followed by spring and autumn, and the summer air quality is good.

In spring, air masses of type 1 are long distances transportation, and the air masses travel fast. They passed through Shaanxi, Shanxi and western Inner Mongolia, accounting for $32.61 \%$, and the average level of $\mathrm{PM}_{2.5}$ is $69.8 \mu \mathrm{g} / \mathrm{m}^{3}$; The trajectories of type 2 account for $23.91 \%$, the average $\mathrm{PM}_{2.5}$ level was $63.45 \mu \mathrm{g} / \mathrm{m}^{3}$ and they passed through the Bohai Sea and Shandong; the maximum level of $\mathrm{PM}_{2.5}$ was the Category 3 trajectory with $90.33 \mu \mathrm{g} / \mathrm{m}^{3}$, accounting for $9.78 \%$; Category 4 trajectory passed through Shandong, Beijing-Tianjin-Hebei, Bohai and other places, the average $\mathrm{PM}_{2.5}$ concentration was the lowest at $42.5 \mu \mathrm{g} / \mathrm{m}^{3}$; the Category 5 trajectory was long-distance transmission, and the transmission speed was fast. The mean value was $65.29 \mu \mathrm{g} / \mathrm{m}^{3}$ and trajectory passed through Shaanxi, Gansu and Ningxia. The trajectory of type6 is short-distance transport, and the air mass moves slowly, accounting for $7.61 \%$, which contributes less to Zhengzhou's pollution.

In summer, the average value of $\mathrm{PM}_{2.5}$ was low, and the pollution status was significantly reduced. The Category 1 trajectories passed through Beijing-Tianjin-Hebei and Bohai, the Category 2 trajectories crossed western Inner Mongolia, Shaanxi, and Shanxi. The Category 3 trajectories passed through Hubei, and the Category 4 air mass cross the Yellow Sea, Jiangsu, and Anhui that accounted for $19.57 \%$. The mean value of $\mathrm{PM}_{2.5}$ of the four types is not much different, but the type 2 transmission speed is faster. In the fifth trajectory crossed
Shandong and Henan, the mean concentration of $\mathrm{PM}_{2.5}$ was the highest, which was $48.33 \mu \mathrm{g} / \mathrm{m}^{3}$, accounting for approximately 13.04\%; the trajectory of the sixth type through Hunan, Hubei and Anhui accounted for the smallest $(8.7 \%)$. The average concentration of PM2 .5 is $42.75 \mu \mathrm{g} / \mathrm{m}^{3}$, which has little effect on $\mathrm{PM}_{2.5}$ in the study area.

In autumn, the first category trajectory mainly came from the northwest of Zhengzhou, passing through western Inner Mongolia, Shaanxi, and Shanxi, the third category passed through Inner Mongolia, Beijing-Tianjin-Hebei, Shandong, and the fifth category trajectory crossed Inner Mongolia and Hebei, respectively accounting for $31.71 \%, 18.29 \%$ and $9.76 \%$, among them, the level of $\mathrm{PM}_{2.5}$ were $71.96 \mu \mathrm{g} / \mathrm{m}^{3}, 53.13 \mu \mathrm{g} / \mathrm{m}^{3}$ and $92.63 \mu \mathrm{g} / \mathrm{m}^{3}$ respectively. The transmission speeds of track 1 and track 5 were faster, and the air mass of track 3 was relatively clean; The mean level of $\mathrm{PM}_{2.5}$ in track 2 and track 4 were $63.18 \mu \mathrm{g} / \mathrm{m}^{3}$ and $68.74 \mu \mathrm{g} / \mathrm{m}^{3}$. We can find that local pollution sources had a great impact on Zhengzhou in the autumn; the Category 6 through Hunan, Hubei and Anhui accounted for $8.7 \%$. The average level of $\mathrm{PM}_{2.5}$ is $42.75 \mu \mathrm{g} / \mathrm{m}^{3}$, which has little effect on Zhengzhou.

In winter, the average $\mathrm{PM}_{2.5}$ concentration was significantly higher than that in other seasons. Among them, the second, fourth, fifth and sixth types of trajectories came from the northwest regions 1 and western regions of Inner Mongolia. The fourth, fifth, and sixth types of trajectories passing through Shaanxi and Shanxi account for $6.23 \%$ in total, and the average level of $\mathrm{PM}_{2.5}$ is $134.43 \mu \mathrm{g} / \mathrm{m}^{3}, 54.36 \mu \mathrm{g} / \mathrm{m}^{3}$ and $127.79 \mu \mathrm{g} / \mathrm{m}^{3}$; $\mathrm{PM}_{2.5}$ of the third type passed through Anhui, Jiangsu, and Shandong and the average level of the type was $217.67 \mu \mathrm{g} / \mathrm{m}^{3}$, accounting for $13.33 \%$; The type 1 trajectories crossed North Sichuan, Gansu, Shaanxi, Hubei and Hubei. The Type 2 trajectories passed through Mongolia, Hebei, and Shandong. And they have the same weight and contribute a lot to Zhengzhou. Obviously, the seasonal variation of air mass clustering is obvious. In winter, the mean $\mathrm{PM}_{2.5}$ concentration is the highest, followed by autumn and spring, and lowest in summer.
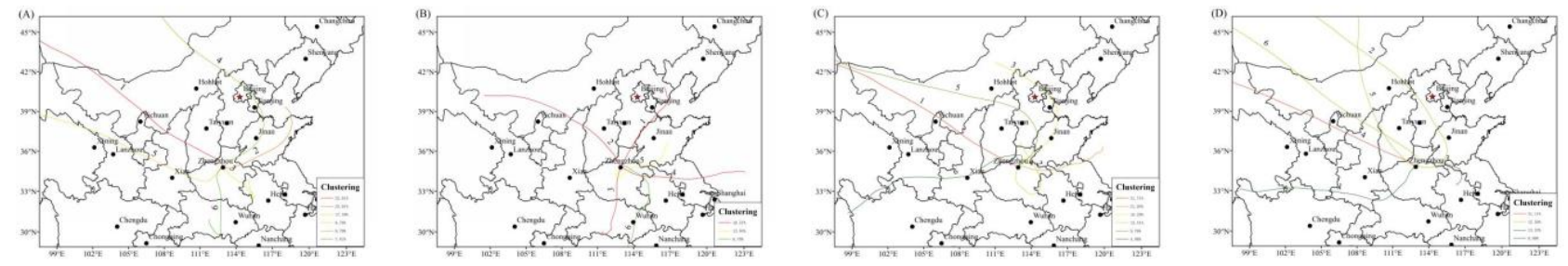

Figure 5 Clustering map of each season in Zhengzhou during 2016 

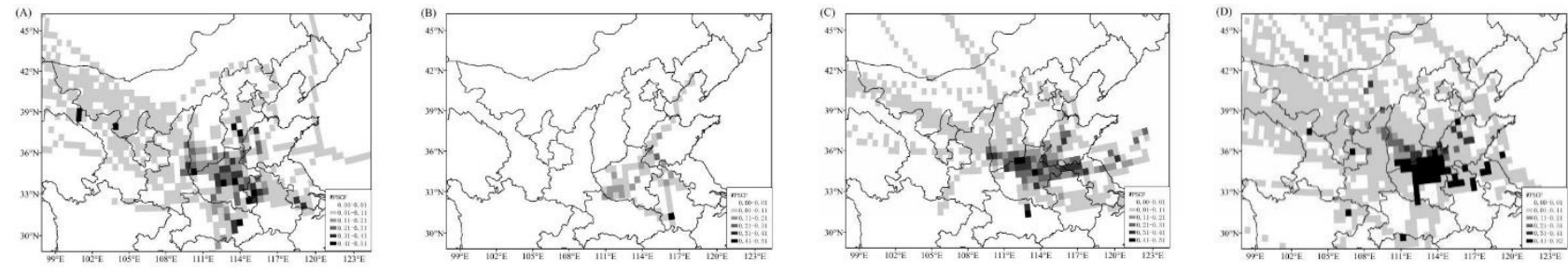

Figure 6 Distribution characteristics of $\mathrm{PM}_{2.5}$ in WPSCF analysis in Zhengzhou during 2016

\subsection{Potential source area analysis of pollutants.}

We used PSCF Analysis of the TrajStat to analyse the distribution of $\mathrm{PM}_{2.5}$ potential sources in Zhengzhou during 2016(figure 6). The darker the grid colour, the larger the WPSCF value, which indicates that the area has great impact on $\mathrm{PM}_{2.5}$ in Zhengzhou, the number of pollution trajectories in this region is more.

The high WPSCF values in spring were found in Hebei, Hubei and Henan, which indicated that these areas have a certain effect on air pollution to Zhengzhou in spring. In summer, the

\section{SUMMARY AND DISCUSSION}

(1) In 2016, the level of $\mathrm{PM}_{2.5}$ in Zhengzhou showed obvious seasonal changes. The level of $\mathrm{PM}_{2.5}$ in spring and winter was high, and the level of $\mathrm{PM}_{2.5}$ in summer and autumn was low. The average level of $\mathrm{PM}_{2.5}$ in December was the highest and the lowest level in August. In the daily variation the level of $\mathrm{PM}_{2.5}$, which is a two-peak structure, the level of $\mathrm{PM}_{2.5}$ reached two peaks at 8 a.m. and 23 p.m. and it reached the lowest value of the day at 17 p.m. During the winter, the hourly average level of $\mathrm{PM}_{2.5}$ is more than $120 \mu \mathrm{g} / \mathrm{m}^{3}$, and the average level of $\mathrm{PM}_{2.5}$ in the whole year is less than $100 \mu \mathrm{g} / \mathrm{m}^{3}$.

(2) In 2016, the level of $\mathrm{PM}_{25}$ in Zhengzhou was affected by meteorological factors in different seasons, and the annual level of $\mathrm{PM}_{2.5}$ was positively correlated with air pressure and relative humidity, and negatively correlated with temperature, visibility, precipitation and wind speed. Among them, the level of $\mathrm{PM}_{2.5}$ was strongly correlated with atmospheric pressure, temperature, visibility and wind speed, however, the correlation with rainfall and relative humidity was weak.

(3) In four seasons, the trajectory of particulate matter in Zhengzhou is divided to 6 types. In winter, the level of $\mathrm{PM}_{2.5}$ of the air trajectory that passed through northern Sichuan-Gansu-Shaanxi-Hubei was the highest, which was $202.13 \mu \mathrm{g} / \mathrm{m}^{3}$. And the air trajectory was long-distance transportation and the transmission speed was fast; In summer the air mass trajectory transmitted from Hubei was the lowest level of $\mathrm{PM}_{2.5}$, which was $40.17 \mu \mathrm{g} / \mathrm{m}^{3}$ and the transmission speed was slow.

(4) In spring, the potential source area appeared in the northwest of Zhengzhou, Gansu, Hubei and BeijingTianjin-Hebei regions. In summer, In summer, the area around Zhengzhou has contributed less to Zhengzhou, and the areas that made great contribution to pollution are were Inner Mongolia, Shanxi, the Yellow sea and Bohai sea. In autumn, the potential source area was located in high WPSCF in Zhengzhou is little smaller, they mainly distributed in Anhui, Henan and Shandong. In autumn, the $\mathrm{PM}_{2.5}$ potential source area of Zhengzhou is internally in Henan, Shandong, Anhui, and yellow sea. It shows that in autumn, Shandong, Henan, Jiangsu and other regions have contributed to the $\mathrm{PM}_{2.5}$ pollution in Zhengzhou. In winter, the potential source of air pollution in Zhengzhou is relatively concentrated, mainly in the north of Zhengzhou, Anhui and Shandong. The rapid increase of particulate matter in the atmosphere has a significant impact on the air quality in Zhengzhou in winter, because people burn coal for warmth.

Shaanxi, Sichuan, Qinghai, Ningxia and Inner Mongolia. In winter, the potential source area was located in Jiangsu, Hubei and Henan, east of Shaanxi, south of Shanxi, Ningxia and the Yellow Sea.

\section{ACKNOWLEDGEMENTS}

Acknowledgements of support for the training Program of Innovation and Entrepreneurship for Undergraduates (201710475053); Key Scientific Research Projects in Colleges and Universities (17A170005); China Postdoctoral fund (2016M602232); Henan Provincial Postdoctoral Science Foundation; The National Natural Science Fund (41671425).;Open Fund of Henan Key Laboratory of Integrated Air Pollution Control and Ecological Security (20170201).

\section{REFERENCES}

Budge, K.G., 2004. Method of and apparatus for modeling interactions. US, pp. 359-365.

Cape, J.N., Methven, J., Hudson, L.E., 2000. The use of trajectory cluster analysis to interpret trace gas measurements at Mace Head, Ireland. Atmos Environ 34, 3651-3663.

Ge, Y., Wang, M.X., Bai, X., Yao, J.B., Zhu, Z.R., 2017. Pollution characteristics and potential sources of $\mathrm{PM}_{2.5}$ in $\mathrm{Su}-$ Xi-Chang Region. Acta Scientiae Circumstantiae, 803-813.

He, T., Peng, Y., Qiao, L.P., Teng, J.Q., Xue, Y.G., Characteristics of Air Pollution and Potential Source in Winter of Changzhou. Environmental Science Research, 1-11.

Jiang, Z.H., Ren, W., Liu, Z.Y., Yang, H., 2013. Analysis of Water Vapor Transport Characteristics During the Meiyu over the Yangtze-Huaihe River Valley using the Lagrangian Method. Acta Meteorologica Sinica, 295-304.

Ke, X.S., Sheng, L.F., Kong, J., Hao, Z.T., Qu, W.J., 2014. Variation of Atmospheric Particle Number Concentrations in 
Qingdao and ItsImpact on Visibility. Environmental Science, 15-21.

Liu, Y.L., Sun, Q.M., Zhong, M.Y., Zhong, B.Q., Luo, K.L., 2016. Temporal and Spatial Distribution Characteristics of $\mathrm{PM}_{2}$ ${ }_{5}$ in Chongqing UrbanAreas. Environmental Science, 1219-1229.

Luo, X.S., Zhao, Z., Chen, Y., Ge, X., Huang, Y., Suo, C., Sun, X., Zhang, D., 2017. Effects of emission control and meteorological parameters on urban air quality showed by the 2014 Youth Olympic Games in China. Fresenius Environmental Bulletin 26, 4798-4807.

Ma, Q.Y., Huang, D.Y., Zhang, H.J., Wang, S.H., Chen, X.F., 2017. Exposure to particulate matter $2.5\left(\mathrm{PM}_{2.5}\right)$ induced macrophage-dependent inflammation, characterized by increased Th1/Th17 cytokine secretion and cytotoxicity. Int Immunopharmacol 50, 139-145.

Mu, C.Y., Tu, Y.Q., Feng, Y., 2011. Effect Analysis of Meteorological Factors on the Inhalable ParticleMatter Concentration of Atmosphere in Hami. Meteorological and Environmental Sciences, 75-79.

Polissar, A.V., Hopke, P.K., Harris, J.M., 2001. Source regions for atmospheric aerosol measured at Barrow, Alaska. Environmental Science \& Technology 35, 4214.

Ren, C.B., Wu, L.X., Zhang, Y.Y., Li, J.L., Chai, M., Xiang, C.C., 2016. Analyze to the seasonal differences of transport pathways and potential source-zones of Beijing Urban $\mathrm{PM}_{2.5}$. China Environmental Science 2591-2598.

Song, Y., Tang, X.Y., Fang, C., Zhang, Y.H., Hu, M., Zeng, L.M., Li, C.C., Mao, J.T., Michael, B., 2003. Relationship between the visibility degradation and particle pollution inBeijing. Acta Scientiae Circumstantiae 468-471.

Wang, A.P., 2014. Aerosol Size Distribution Measurement and Potential Sources \& Transport of Mountain Huang. Nanjing University of Information Technology.

Wang, F., Chen, D.S., Cheng, S.Y., Li, M.J., 2009a. Impacts of Air Pollutant Transport Based on Air Trajectory Clustering. Research of Environmental Sciences, 637-642.

Wang, G.C., Wang, D.Q., Chen, Z.L., 2016. Characteristics and transportation pathways and potential sources of a severe $\mathrm{PM}_{2.5}$ episodes during winter in Beijing. . China Environmental Science 1931-1937.

Wang, G.C., Wang, J., Xin, Y.J., Chen, L., 2014. Transportation pathways and potential source areas of $\mathrm{PM}_{10}$ and $\mathrm{NO}_{2}$ in Tianjin. China Environmental Science, 3009-3016.

Wang, J., Hu, Z.M., Chen, Y.Y., Chen, Z.L., Xu, S.Y., 2013. Contamination characteristics and possible sources of $\mathrm{PM}_{10}$ and $\mathrm{PM}_{2.5}$ in different functional areas of Shanghai, China. Atmos Environ 68, 221-229.

Wang, L., Liu, Z., Sun, Y., Ji, D., Wang, Y., 2015. Long-range transport and regional sources of $\mathrm{PM}_{2.5}$ in Beijing based on long-term observations from 2005 to 2010. Atmospheric Research 157, 37-48.

Wang, Y.Q., Zhang, X.Y., Draxler, R.R., 2009b. TrajStat: GISbased software that uses various trajectory statistical analysis methods to identify potential sources from long-term air pollution measurement data. Environmental Modelling \& Software 24, 938-939.

Xia, D., Wu, Z.Q., Mo, W.Q., Tan, H.B., 2013. Analysis of a Haze Process Caused by Peripheral Subsidence of Tropical Cyclones over the Pearl River Delta Region. Meteorological Monthly, 759-767.

Yan, X.Y., Gou, X.H., Wu, W.L., Huang, F., Yang, J., Liu, Y.L., Analysis of atmospheric particulate transport path and potential source area in Yinchuan Acta Scientiae Circumstantiae 1-16.

Yang, X.C., Zhao, W.J., Xiong, Q.L., Wang, L.L., Zhao, W.H., 2017. Spatio-temporal distribution of $\mathrm{PM}_{2.5}$ in BeijingTianjin-Hebei (BTH) area in 2016 and its relationship with meteorological factors Ecology and Environmental Sciences, $1747-1754$.

Zhao, H., Wang, T.J., Jiang, F., Xie, M., 2009. Investigation into the Source of Air Pollutions to Hong Kong by using Backward Trajectory Method During the TRACE-P Campaign. Journal of Tropical Meteorology 181-186.

Zhao, M., Huang, Z., Qiao, T., Zhang, Y., Xiu, G., Yu, J., 2015a. Chemical characterization, the transport pathways and potential sources of PM 2.5 in Shanghai: Seasonal variations. Atmospheric Research 158-159, 66-78.

Zhao, Q.B., Hu, M., Zhang, Y.H., 2014. Study of Source Distribution and Transportation Characteristics of $\mathrm{PM}_{2.5}$ in Shanghai using Backward Trajectory Model. Environmental Monitoring Management and Technology, 22-26.

Zhao, Y., Hu, G.R., Yu, R.L., Lu, C.W., Fan, X.J., Huang, L.G., Liu, H.T., 2017. Concentrations and Spatial-Temporal Characteristics and Source Analysis ofPM ${ }_{2.5}$ in Nanchang City in 2013. Research of Environmental Sciences, 854-863.

Zhao, Z.Q., Wei, Y.J., Zhang, X.Z., Qin, W., Xie, H.F., 2015 b. The correlation analysis of Nanjing haze days and meteorological factors. . China Environmental Science $3570-3580$

Zhou, S., Liu, N., Liu, C.S., 2017a. Identification for potential sources for haze events in Shanghai from 2013 to 2015. Acta Scientiae Circumstantiae, 1835-1842.

Zhou, W., Tian, D.D., He, J., Zhang, L., Tang, X.L., Zhang, L.J., Wang, Y.M., Li, L.Z., Zhao, J., Yuan, X.Y., Peng, S.Q., 2017b. Exposure scenario: Another important factor determining the toxic effects of $\mathrm{PM}_{2.5}$ and possible mechanisms involved. Environ Pollut 226, 412-425.

Zhu, W., Luo, L., Cheng, Z., Yan, N., Lou, S., Ma, Y., 2017. Characteristics and contributions of biogenic secondary organic aerosol tracers to $\mathrm{PM}_{2.5}$ in Shanghai, China. Atmospheric Pollution Research. 